\title{
Can we fix it?
}

\author{
Mitigation of climate change is increasingly being portrayed as technologically feasible, if only political \\ support was adequate. But there are good reasons to be unsure.
}

One way of shaping the future is positive thinking: high expectations can turn into a self-fulfilling prophecy. Climate scientists seem to have discovered this idea for themselves. In academic circles, the fear has spread that politicians and the public may give up on tackling global warming if they see it as a lost cause. In response, the tenor of the public debate has shifted. An optimistic tone has replaced the doom-andgloom scenarios that once characterized the media statements of climate scientists. And the dangers of climate change are now more often described as serious but quite manageable - as long as there is political will.

Perhaps the turning point goes back to the concept of 'stabilization wedges' - the idea that a portfolio of existing technologies can add up to a mitigation effort that provides the world with energy, while keeping atmospheric carbon dioxide concentrations below a reasonable level (Science 305, 968-972; 2004). Adding up the benefits of a range of available methods - such as efficiency gains, replacing fossil fuels by nuclear power or renewable energy, carbon capture and storage, and carbonconserving land-use changes made a large and looming problem sound much more tractable.

But a conversation on 3 November 2010 between Canada's famous novelist and poet, Margaret Atwood, and climate scientist Brian Hoskins, brought to light the scepticism that the public feel (http:// royalsociety.org/A-problemshared-securing-a-futurefor-our-planet/). At the event - hosted by the UK's Royal Society and the Royal Society of Literature Hoskins argued that carbon dioxide emissions can be brought under control, at least in the UK, using existing technologies. "We don't need a magic wand," he said, "we just need to do it." Atwood remained sceptical. Her pertinent questions regarding developments in the US, the interests of oil companies and the impacts of coal burning were countered, but not entirely conclusively.

Indeed, one audience member criticized what he termed the "Bob the Builder approach" to climate change promoted by climate scientists. A credo of "Can we fix it? Yes we can!" simply doesn't ring true with the concerned public. Anyone who has suffered a damp wall in their house will know that in the real world, even fixes in Bob the Builder's home territory are rarely straightforward. So why the solution to a problem as complex as climate change should rely on political will alone is not obvious.

For a start, the human dimension changes in behaviour in response to mitigation efforts should not be underestimated. For example, a future increase in the energy efficiency of lighting technology is more likely to lead to more and brighter artificial light in

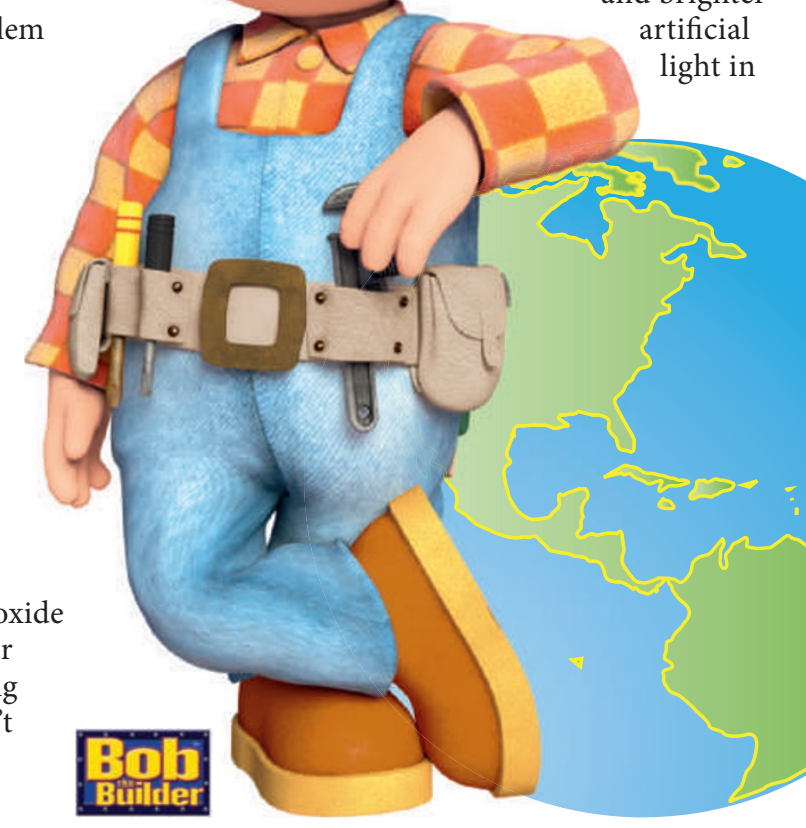

people's lives, than to a downturn in energy consumption (J. Phys. D 43, 354001; 2010). Similarly, it is hard to predict whether efficiency gains more generally will result in a reduction in carbon dioxide emissions or in higher energy usage. Yet improvements in energy efficiency are key to plans to achieve a carbon-free economy.

Globalization is not necessarily helpful either. As reported on p811 of this issue, the drop in carbon dioxide emissions in 2009 as a result of the financial crisis did not match expectations (Nature Geosci. 2, 831-836; 2009), partly because of a shift in economic growth from the developed world to emerging economies. There, reliance on coal is high, and more carbon dioxide is emitted per unit of gross domestic product. The shift in manufacturing towards emerging economies looks set to continue. Whether a transfer of less-carbon-intensive technologies from the developed world can keep up, and keep emissions down, is unclear.

Nor will geoengineering solve the problem. Solar radiation management and carbon sequestration technologies may become useful as an emergency fall-back plan, or as a way to ease the transition to a carbon-free world, but not as a long-term solution. Despite a quick rise in the number of research papers on geoengineering, many of those involved in the science are deeply uncomfortable with the concept itself, or at least with the speed at which it is developing (http://www.economist.com/ node/17414216)

When asked for the lessons learnt from last year's 'climategate' affair, climate researchers tend to make two points: the need for greater transparency, and the need for clearer communication of associated uncertainties. To take the second part of that lesson seriously, perhaps next time someone asks "can we fix climate change?" the answer should be "We don't know." 